\begin{tabular}{l|l|}
\cline { 2 - 2 } 1 & This is the final draft post-refereeing. \\
2 & The publisher's version can be found at \\
3 & http://dx.doi.org/10.1016/j.foodchem.2007.08.082 \\
4 & Please cite this article as: Lagrain, B., Thewissen, B.G., Brijs, K., Delcour J.A. \\
5 & Mechanism of gliadin-glutenin cross-linking during hydrothermal treatment, Food \\
6 & Chemistry 2008, 107, 753-760.
\end{tabular}

\title{
Mechanism of gliadin-glutenin cross-linking during hydrothermal treatment
}

$14 *$ Corresponding author:

15 Bert Lagrain

16 Tel: $+32(0) 16321634$

17 Fax: + $32(0) 16321997$

18 E-mail address: bert.lagrain@biw.kuleuven.be 


\section{Abstract}

22 The gluten proteins gliadin and glutenin are important for wheat flour functionality and

23 they undergo changes during heat treatment involving sulfhydryl ( $\mathrm{SH}$ ) groups. To change

24 the level of SH-groups during hydrothermal treatment, the oxidant potassium iodate (2.1

$25 \mu \mathrm{mol} / \mathrm{g}$ protein) and the reducing agent dithiothreitol (DTT, $6.1 \mu \mathrm{mol} / \mathrm{g}$ protein) were added

26 to $20 \%(\mathrm{w} / \mathrm{w})$ gluten-in-water suspensions at room temperature, at $90{ }^{\circ} \mathrm{C}$ and after $15 \mathrm{~min}$

27 at $95^{\circ} \mathrm{C}$ and the viscosity was measured by the Rapid Visco Analyser (RVA). Protein

28 extractabilities after hydrothermal treatment were determined with size-exclusion and

29 reversed-phase HPLC. DTT decreased maximal RVA viscosity and the levels of extractable

$30 \alpha$ - and $\gamma$-gliadin and this decrease was independent of the time of addition during

31 hydrothermal treatment. In contrast, potassium iodate increased the levels of extractable $\alpha$ -

32 and $\gamma$-gliadin. Its impact was less when added at later times during RVA analysis. A SH-

33 blocking agent ( $\mathrm{N}$-ethylmaleimide, $8.0 \mu \mathrm{mol} / \mathrm{g}$ protein) added at room temperature to the

34 gluten suspension, decreased RVA viscosity at $95{ }^{\circ} \mathrm{C}$ and increased the extractabilities of

35 glutenin and $\alpha$ - and $\gamma$-gliadin after hydrothermal treatment. Subsequent addition at $90{ }^{\circ} \mathrm{C}$ of

36 a reducing agent (glutathione, 3.1 and $6.2 \mu \mathrm{mol} / \mathrm{g}$ protein) recovered the control RVA

37 profile and restored the control protein extractabilities after RVA analysis. This shows the

38 importance of heat-induced gliadin-glutenin reactions for gluten viscosity and of the

39 presence of free $\mathrm{SH}$-groups for the polymerization of gluten proteins. A model explaining

40 gliadin-glutenin polymerization through a sulfhydryl-disulfide exchange mechanism and

41 demonstrating the effects of redox agents is put forward. 
43 Abbreviations: db, dry basis; DTT, dithiothreitol, GSH, glutathione; HPLC, high

44 performance liquid chromatography; NEMI, N-ethylmaleimide; RP, reversed-phase; SDS, 45 sodium dodecyl sulfate; SE, size-exclusion; SH, sulfhydryl; SS, disulfide

46

47

48 Keywords: Wheat gluten, Heat treatment, Gliadin-glutenin interaction, Protein

49 extractability, $\quad$ Redox agents, Thiol-disulfide interchange 


\section{Introduction}

51 The storage proteins of wheat (consisting of monomeric gliadin and polymeric glutenin) are

52 very important for wheat flour functionality. They have the unique rheological ability to

53 form a dough matrix which determines bread quality. Gliadin represents a heterogeneous

54 mixture of proteins containing $\alpha$-, $\gamma$-, and $\omega$-gliadins. All cysteine residues in $\alpha$ - and $\gamma$-type

55 gliadins are involved in intra-chain disulfide (SS) bonds. In contrast, $\omega$-gliadins lack

56 cysteine residues. Glutenin consists of glutenin subunits (GS) of high molecular weight

57 (HMW-GS) and low molecular weight (LMW-GS). The LMW-GS are classified as B-, C-,

58 and D-types. LMW-GS form both intra-chain and inter-chain disulfide bonds among

59 themselves and with HMW-GS leading to glutenin polymers (Veraverbeke \& Delcour,

60 2002). Heat treatment of these proteins strongly influences the characteristics of baked

61 products. The changes induced by heat eventually lead to large gluten protein aggregates

62 with formation of gliadin-glutenin bonds through SS (cross-)linking in the process

63 (Lagrain, Brijs, Veraverbeke \& Delcour, 2005; Morel, Redl \& Guilbert, 2002; Redl, Morel,

64 Bonicel, Vergnes \& Guilbert, 1999; Schofield, Bottomley, Timms \& Booth, 1983; Singh \&

65 MacRitchie, 2004). Lagrain et al. (2005) applied a temperature profile and simultaneously

66 measured rheological changes of a gluten-water suspension in the Rapid Visco Analyser

67 (RVA). When the temperature was increased to $95^{\circ} \mathrm{C}$, mainly the glutenin extractability

68 decreased. The polymerization of glutenin may involve oxidation (Singh et al., 2004) and

69 sulfhydryl (SH)-SS exchange (Lagrain et al., 2005). Holding at $95{ }^{\circ} \mathrm{C}$ resulted in

70 polymerization of both gliadin and glutenin and this caused a viscosity rise in the RVA

71 profile (Lagrain et al., 2005). Oxidizing agents decreased RVA viscosities in the holding

72 step and increased sodium dodecyl sulfate (SDS) protein extractabilities suggesting 
73 decreased gliadin-glutenin cross-linking. In contrast, reducing agents increased RVA 74 viscosity at lower temperatures and lowered SDS extractabilities. It was postulated that 75 addition of reducing agent facilitates gliadin-glutenin cross-linking during heating while 76 oxidants hinder gluten polymerization due to decreased levels of free SH-groups and less 77 flexibility of the glutenin chains (Lagrain, Brijs \& Delcour, 2006). These observations were 78 ascribed to a SH-SS exchange mechanism (Lagrain et al., 2006) as originally proposed by 79 (Schofield et al., 1983). This was concluded from the observation that the total level of free 80 SH-groups remained constant irrespective of the temperature (Schofield et al., 1983). 81 Recently, an SH-SS exchange mechanism in gluten was also observed under high pressure 82 (Schurer, Kieffer, Wieser \& Koehler, 2007) and in bread making (Lagrain, Thewissen, 83 Brijs \& Delcour, 2007). The SH-SS exchange mechanism requires free SH-groups. Thus, 84 changes in the level of free SH during hydrothermal treatment should affect gliadin85 glutenin association.

86 To further increase insight into the mechanism of the covalent association between gliadin 87 and glutenin during hydrothermal treatment, the aim of the present work is to investigate 88 the importance of free SH-groups at certain temperatures. To this end, RVA viscosities and 89 protein extractabilities were measured in the presence of redox additives. 


\section{Experimental}

91 2.1. Materials

92 All reagents were at least of analytical grade and from Sigma-Aldrich (Steinheim,

93 Germany) unless otherwise specified. Vital wheat gluten [moisture content: $6.10 \%$, crude 94 protein content $(\mathrm{N} \times 5.7)$ : $83.5 \%$ on dry basis $(\mathrm{db})$, starch content: $10.4 \%$ on $\mathrm{db}$ ] was 95 obtained by industrial gluten-starch separation of European spring wheat flour by Tate \& 96 Lyle Europe (Aalst, Belgium). The gluten powder passed through a $250 \mu \mathrm{m}$ sieve.

98 2.2. Controlled heating and cooling

99 A Rapid Visco Analyser (RVA-4D, Newport Scientific, Sydney, Australia) was used to 100 apply a temperature profile to $25.00 \mathrm{~g}$ of $20 \%(\mathrm{w} / \mathrm{w})$ suspensions of control gluten in the 101 presence or absence of additives (Lagrain et al., 2006). The RVA converts the current 102 required to maintain constant mixing speed $(160 \mathrm{rpm})$ of a paddle into a viscosity value in 103 Poise (P, $0.1 \mathrm{~kg} \mathrm{~m}-1 \mathrm{~s}-1)$, the unit of dynamic viscosity. This viscosity value is further 104 referred to as RVA viscosity. At the start of the RVA analysis, suspensions were 105 homogenized by hand-shaking and mixing (900 rpm for $20 \mathrm{~s}$ ). The temperature profile 106 included a temperature increase from room temperature to $40{ }^{\circ} \mathrm{C}$ (in $1 \mathrm{~min}$ ), a linear 107 temperature increase to $95^{\circ} \mathrm{C}$ in $14 \mathrm{~min}$, a holding step (40 min at $95^{\circ} \mathrm{C}$ ), a cooling step (7 $108 \mathrm{~min})$ with a linear temperature decrease to $50{ }^{\circ} \mathrm{C}$, and a final holding step at $50{ }^{\circ} \mathrm{C}(13$ $109 \mathrm{~min})$. Potassium iodate $(2.1 \mu \mathrm{mol} / \mathrm{g}$ protein $)$ or dithiothreitol $(6.1 \mu \mathrm{mol} \mathrm{DTT} / \mathrm{g}$ protein $)$ 110 were added as aqueous solutions $(200 \mu \mathrm{l})$ immediately before RVA analysis, after 13 min 111 (at $90{ }^{\circ} \mathrm{C}$ ) and after $30 \mathrm{~min}$ (after $15 \mathrm{~min}$ at $\left.95^{\circ} \mathrm{C}\right)$. N-ethylmaleimide $(8.0 \mu \mathrm{mol} \mathrm{NEMI} / \mathrm{g}$ 112 protein) was added as aqueous solution $(200 \mu \mathrm{l})$ immediately before RVA analysis. At 90 
$113{ }^{\circ} \mathrm{C}, 3.1$ or $6.2 \mu \mathrm{mol}$ glutathione $(\mathrm{GSH}) / \mathrm{g}$ protein was added to the suspension with NEMI.

114 After RVA analysis, the gluten suspensions were frozen in liquid nitrogen, freeze-dried and

115 ground in a laboratory mill (IKA, Staufen, Germany). Three characteristic viscosity values

116 were recorded. The initial viscosity, the highest viscosity (in $\mathrm{cP}$ ) at the start of the RVA

117 run; the minimal viscosity, the lowest viscosity before the holding step; and the maximal

118 viscosity, the highest viscosity in the holding step at $95{ }^{\circ} \mathrm{C}$ (Lagrain et al., 2006). All RVA

119 analyses were performed at least in triplicate. The standard deviations calculated for the

120 initial, the minimal and the maximal viscosities were less than $10 \%$ of the respective mean

121 values.

123 2.3. Size-exclusion HPLC

124 SE-HPLC was conducted using a LC-2010 system (Shimadzu, Kyoto, Japan) with 125 automatic injection. Freeze-dried gluten samples $(1.0 \mathrm{mg})$ were shaken with $1.0 \mathrm{ml}$ of a $1260.05 \mathrm{M}$ sodium phosphate buffer $(\mathrm{pH}$ 6.8) containing 2.0\% SDS for 60 min at room 127 temperature. After centrifugation $(5 \mathrm{~min}, 10000 \mathrm{~g})$, the supernatant $(60 \mu \mathrm{l})$ was loaded on a 128 Biosep-SEC-S4000 column (Phenomenex, Torrance, United States). The elution solvent 129 was $(1: 1, \mathrm{v} / \mathrm{v})$ acetonitrile $(\mathrm{ACN}) /$ water containing $0.05 \%(\mathrm{v} / \mathrm{v})$ trifluoroacetic acid $(\mathrm{TFA})$. 130 The flow rate was $1.0 \mathrm{ml} / \mathrm{min}$ at a temperature of $30{ }^{\circ} \mathrm{C}$ (Dachkevitch \& Autran, 1989) and 131 eluted protein was detected at $214 \mathrm{~nm}$.

132 The elution profiles were divided into two fractions using the lowest absorbance reading 133 between the two peaks as the cutoff point. The first fraction corresponded to the level of 134 SDS extractable glutenin, the second was assigned to the level of SDS extractable gliadin. 135 Total SDS extractable protein, gliadin and glutenin were calculated from the peak areas and 
136 expressed as percentage of the peak area of unheated gluten extracted with the SDS buffer 137 in the presence of $1.0 \%$ DTT.

\subsection{Reversed-phase HPLC}

140 Samples (100.0 mg) were extracted three times with $3.0 \mathrm{ml} 60 \%$ (v/v) ethanol (gliadin 141 extract) and three times with $3.0 \mathrm{ml} 0.05 \mathrm{M}$ Tris/ $\mathrm{HCl}$ buffer ( $\mathrm{pH} \mathrm{7.5)} \mathrm{containing} 50 \%$ 142 propan-1-ol, 2.0 M urea and 1\%(w/v) DTT and kept under nitrogen (reduced glutenin 143 extract). The gliadin and glutenin extracts were loaded $(80 \mu \mathrm{l})$ on a Nucleosil 300-5 C8 144 column (Machery-Nagel, Düren Germany). The elution system consisted of deionised 145 water $+0.1 \%(\mathrm{v} / \mathrm{v})$ TFA (A) and $\mathrm{ACN}+0.1 \% \mathrm{TFA}(\mathrm{v} / \mathrm{v})(\mathrm{B})$. Proteins were eluted with a 146 linear gradient from $24 \% \mathrm{~B}$ to $56 \% \mathrm{~B}$ in $50 \mathrm{~min}$ and detected at $214 \mathrm{~nm}$.

$147 \alpha$-Gliadin, $\gamma$-gliadin, $\omega$-gliadin, B/C-LMW-GS, D-LMW-GS and HMW-GS were 148 distinguished based on absorbance minima between specific peaks as outlined earlier by 149 Wieser, Antes \& Seilmeier (1998).

$151 \quad$ 2.5. Statistical analysis of data

152 Significant differences $(\mathrm{P}<0.05)$ in initial, minimal and maximal RVA viscosities were 153 determined by the ANOVA procedure using the SAS package (SAS system for Windows 154 V8, SAS Institute Inc., Cary, NC, USA) and were based on at least three individual 155 measurements. 


\section{3. Results and Discussion}

1583.1 Addition of redox agents at different points during RVA analysis

159 The impact on RVA viscosity of the addition of $6.1 \mu \mathrm{mol} \mathrm{DTT} / \mathrm{g}$ protein $(800 \mathrm{ppm})$ at 0 $160 \mathrm{~min}$, at $13 \mathrm{~min}\left(90^{\circ} \mathrm{C}\right)$ and at $30 \mathrm{~min}\left(\right.$ after $15 \mathrm{~min}$ at $\left.95^{\circ} \mathrm{C}\right)$ during hydrothermal treatment 161 of a $20 \%(\mathrm{w} / \mathrm{w})$ gluten-in-water suspension is shown in Figure 1. The control gluten 162 suspension showed a substantial initial RVA viscosity which decreased when the 163 temperature was raised to $90{ }^{\circ} \mathrm{C}$. In the holding step $\left(95{ }^{\circ} \mathrm{C}\right)$, the RVA viscosity steadily

164 increased. During cooling, the RVA viscosity decreased again and, in the final holding step 165 at $50{ }^{\circ} \mathrm{C}$, no viscosity changes were observed (Fig. 1). These effects were previously 166 described by Lagrain et al. (2005). The interaction between gliadin and glutenin is 167 responsible for the initial RVA viscosity (Lagrain et al., 2005). The decrease of RVA 168 viscosity during heating can be ascribed to changes in physico-chemical properties of the 169 gluten proteins, such as conformational changes and a loss of hydrogen bonds, which 170 readily break on heating. The viscosity rise in the RVA profile at temperatures exceeding $17190{ }^{\circ} \mathrm{C}$ was caused by formation of large glutenin polymers with the incorporation of gliadin 172 through SS bonds impacting the rotation of the RVA paddle. The sudden decrease in 173 apparent viscosity during cooling was due to the protein polymers aggregating tightly and 174 sticking to the paddle caused by the loss of kinetic energy from heating (Lagrain et al., 175 2005). Addition of $6.1 \mu \mathrm{mol}$ DTT/g protein before RVA analysis resulted in initial, 176 minimal, and maximal viscosities that were all significantly lower $(\mathrm{P}<0.05)$ than the 177 control viscosities (Table 1). Minimal viscosity was reached at lower temperatures (Fig. 1). 178 Addition of DTT at 13 or 30 min still resulted in a significantly lower maximal viscosity 179 (Table 1). Heating gluten suspensions first decreased glutenin extractability and, during 
180 holding at $95^{\circ} \mathrm{C}$, also gliadin extractability (Lagrain et al., 2005). The effect of the addition 181 of $6.1 \mu \mathrm{mol}$ DTT/g protein on protein SDS extractability after RVA analysis was the same 182 for the addition after 0,13 or 30 min (Table 2). Addition of DTT decreased both gliadin 183 and glutenin SDS extractabilities of control gluten after hydrothermal treatment. The 184 decrease in gliadin extractability could be attributed to a decrease in $\alpha$ - and $\gamma$-gliadin 185 extractabilities as calculated from RP-HPLC data (Fig. 2). The levels of $\alpha$-gliadin and $\gamma$ 186 gliadin decreased drastically after RVA analysis of control gluten, to respectively $13 \%$ and $1876 \%$ of their original values, whereas that of $\omega$-gliadin only slightly decreased to $73 \%$ of its 188 original extractability. Addition of DTT did not affect $\omega$-gliadin extractability after RVA 189 analysis, but $\alpha$ - and $\gamma$-gliadin became nearly unextractable in $60 \%$ ethanol (Fig. 2), 190 irrespective whether DTT was added at 0,13 or 30 min during RVA analysis. The decrease 191 in extractable gliadin levels after hydrothermal treatment (Fig. 2a) was accompanied by a 192 significant increase in the apparent levels of the glutenin subunits (Fig. 2b), suggesting that 193 a major portion of gliadins, unextractable in $60 \%$ ethanol after heat treatment, became 194 extractable in the glutenin fraction. This resulted mainly in an apparent increased 195 proportion of B/C-LMW-GS. The total amount of extractable protein (gliadin + glutenin) 196 after complete reduction lowered when holding gluten at $95^{\circ} \mathrm{C}$ for $15 \mathrm{~min}$ and longer in the 197 RVA (Lagrain et al., 2005) and this effect was enhanced with the addition of DTT, 198 suggesting a greater heat sensitivity of gluten proteins in the presence of a reducing agent.

199 While adding $2.1 \mu \mathrm{mol}$ potassium iodate/g protein at the start of RVA analysis resulted in 200 almost no viscosity increase in the holding step, the addition at $13 \mathrm{~min}$ or at $30 \mathrm{~min}$ led to a 201 maximal viscosity that did not differ significantly from the control viscosity (Figure 3, 202 Table 1). Potassium iodate increased the protein extractabilities at the end of the RVA run 
203 compared to the control after hydrothermal treatment, but to a lesser extent than added at 204 later points during hydrothermal treatment. The effect could be ascribed to both higher 205 glutenin and gliadin extractabilities (Table 2). More specifically, the addition of potassium 206 iodate mainly resulted in increased $\alpha$ - and $\gamma$-gliadin extractabilities after RVA analysis 207 accompanied by apparent decreases in LMW-GS compared to the control after 208 hydrothermal treatment (Figure 4). The sum of the levels of extractable gliadin and glutenin 209 after reduction was higher in the presence of potassium iodate after RVA treatment, but it 210 decreased when iodate was added later in the process approaching the levels of control total 211 extractability (results not shown).

212 Reducing agents, such as DTT, facilitate gliadin-glutenin cross-linking during heating. This 213 effect depends on the available concentration of SH-groups in the system (Lagrain et al., 214 2006). Therefore, DTT addition had the strongest effect on the solubility because of the 215 highest concentration of SH-groups. In the control gluten suspension, the SH-concentration 216 was lower, and, hence, the extent of SH-SS interchange was lower than when DTT was 217 added. Moreover the effect of DTT was independent of the time of addition during 218 hydrothermal treatment. Thus, the introduction of a certain level of free SH-groups at any 219 time during hydrothermal treatment results in proportionally more gliadin-glutenin cross220 linking and less extractability of the proteins even after total reduction. In contrast, oxidants 221 lower the level of free SH and decrease glutenin flexibility. This hinders SH-SS exchange 222 reactions between gliadin and glutenin that normally occur at temperatures of at least $90{ }^{\circ} \mathrm{C}$ 223 (Lagrain et al., 2006). As such, oxidizing agents terminate gluten polymerization at that 224 specific point of their addition during hydrothermal treatment with, depending on their 225 concentration, little if any further reaction afterwards. Since $\omega$-gliadins do not contain SH- 
226 groups, they are not involved in SH-SS exchange reactions and their extractability is not

227 influenced by redox agents.

\subsection{Combination of NEMI and glutathione}

230 The gluten proteins contained about $8.0 \mu \mathrm{mol}$ free $\mathrm{SH}$ per g protein (Lagrain et al., 2005).

231 Addition of an equimolar level of the SH-blocking agent NEMI to the gluten suspension

232 resulted in an RVA profile with no viscosity increase in the heating and holding phases

233 (Fig. 5). Potassium iodate and NEMI had similar effects on RVA viscosity (Fig 3 and 5).

234 Subsequent addition of increasing concentrations of reducing agent with one SH-group

235 (GSH) at minimal RVA viscosity (after $13 \mathrm{~min}$ and at $90{ }^{\circ} \mathrm{C}$ ) increased RVA viscosity at

$23695{ }^{\circ} \mathrm{C}$, and $6.2 \mu \mathrm{mol} \mathrm{GSH} / \mathrm{g}$ protein restored the control RVA profile (Fig. 5). NEMI

237 increased gliadin and, to a lesser extent, glutenin extractabilities after heat treatment of the

238 control, suggesting less gliadin-glutenin reactions. Subsequent addition of increasing GSH

239 concentrations decreased protein extractabilities to approximate those of a control

240 suspension at $6.2 \mu \mathrm{mol} \mathrm{GSH} / \mathrm{g}$ protein. This was reflected in decreased $\alpha$ - and $\gamma$-gliadin

241 extractabilities and apparent increases in LMW-GS extractabilities after RVA analysis over

242 the control extractability (Fig. 6).

243 The addition of $8.0 \mu \mathrm{mol} \mathrm{NEMI/g}$ protein may alkylate and, as such, block the free SH-

244 groups that were measured in unheated gluten proteins. Apparently this did not suffice to

245 completely prevent further glutenin polymerization, since glutenin extractability decreased

246 even in the presence of such a concentration of NEMI (Table 3). Addition of higher

247 concentrations of NEMI (100 $\mu \mathrm{mol} / \mathrm{g}$ protein) had similar effects on RVA viscosity

248 (Lagrain et al., 2005), but completely inhibited the effect of hydrothermal treatment on 
249 protein extractability with no change in gliadin and glutenin extractabilities after heating

250 (results not shown). The fact that low concentrations of NEMI could not totally inhibit

251 further glutenin linking during heating, indicates the possible exposure of previously

252 inaccessible free SH-groups by conformational changes. Such groups may induce glutenin

253 linking mainly through oxidation. This then would result in almost no free SH-groups at 95

$254{ }^{\circ} \mathrm{C}$ preventing gliadin-glutenin cross-linking.

255 The addition of $\mathrm{GSH}$ at $90{ }^{\circ} \mathrm{C}$ after $\mathrm{SH}$ blocking probably restored the ability of gliadin to

256 link to glutenin through a SH-SS exchange mechanism. However, in comparison to the

257 control, the alkylated SH-groups were no longer accessible for reduction and, therefore, the

258 protein extractability after addition of GSH approximated, but did not completely reached

259 the control extractabilities.

\subsection{Model of gliadin-glutenin cross-linking}

262 As a whole, our results combined with earlier studies (Guerrieri, Alberti, Lavelli \& Cerletti,

263 1996; Singh et al., 2004) lead to a view on gliadin-glutenin reactions and the impact of

264 oxidants and reducing agents therein that we visualize in Figure 7. Glutenin is presented as

265 a large molecule containing free SH-groups, while gliadin is a smaller molecule with only

266 intramolecular SS bonds and, hence, no free SH-moieties. Heating to $90{ }^{\circ} \mathrm{C}$ first resulted in

267 conformational changes exposing previously unavailable areas (Guerrieri et al., 1996)

268 possibly containing free SH-groups and, next, polymerization of glutenin with oxidation of

269 most but not all SH-groups (Lagrain et al., 2005; Singh et al., 2004). At $90{ }^{\circ} \mathrm{C}$ still some

270 free SH-groups can be measured (Lagrain et al., 2006; Lagrain et al., 2005). At

271 temperatures exceeding $90{ }^{\circ} \mathrm{C}$, these free $\mathrm{SH}$-groups of glutenin can induce a covalent 
272 linkage with gliadin through a heat induced SH-SS exchange mechanism. This exchange 273 reaction is catalyzed by $\mathrm{SH}$-groups and readily occurs in (other) proteins at higher

274 temperatures. The free SH-group carries out nucleophilic attack on the sulfur atom of a 275 disulfide (Volkin \& Klibanov, 1987). It is probable that conformational changes at $90{ }^{\circ} \mathrm{C}$ in 276 the gluten proteins (Guerrieri et al., 1996) are necessary for gliadin-glutenin cross-linking. 277 Addition of a reducing agent, such as DTT, increases the level of free SH-groups. Before 278 heating this first leads to depolymerization of protein-protein disulfides with the formation 279 of proteins with free SH-groups. At higher temperatures, these free SH-groups increase the 280 level of gliadin-glutenin cross-linking. These observations were also made for gluten under 281 high pressure in the presence of cysteine supporting the hypothesis of an ionic mechanism 282 for SH-SS exchange reactions in gluten proteins such as stated by Schurer et al. (2007). In 283 contrast, the presence of NEMI or an oxidant such as potassium iodate decreases the level 284 of free SH-groups (Lagrain et al., 2006) leaving little if any free SH-groups in glutenin and 285 hence little if any gliadin-glutenin cross-linking at temperatures exceeding $90^{\circ} \mathrm{C}$. However, 286 subsequent addition of a reducing agent (e.g. GSH) containing at least one free SH-group, 287 leads to incorporation of this group in glutenin and, as such, gliadin-glutenin cross-linking 288 becomes possible again (Fig. 7). The subsequent addition of reducing agent at $90{ }^{\circ} \mathrm{C}$ can 289 restore the control situation at this temperature. This then will lead to a similar level of 290 gliadin-glutenin cross-linking with the recovery of the control RVA profile (Fig. 5) and the 291 control SDS extractability (Table 3). 
294 We can conclude that, at any time during hydrothermal treatment, free SH-groups initiate 295 gliadin-glutenin reactions at higher temperatures. The extent of these reactions depends on 296 the available concentration of SH-groups in the system. Removing such groups by addition 297 of an oxidant or a SH blocking agent strongly reduces the extent to which gliadin becomes 298 unextractable. By subsequently increasing the level of free SH-groups by adding a reducing 299 agent, the capacity of gliadin to link to glutenin is restored. These findings can contribute to 300 more insight in the impact of redox agents in cereal based processes such as bread, pasta, 301 and cookie production.

302

303 


\section{Acknowledgements}

305 K. Brijs wishes to acknowledge the Industrial Research Fund (K.U.Leuven, Leuven,

306 Belgium). Financial support was obtained from the Institute for the Promotion of 307 Innovation through Science and Technology in Flanders (IWT-Vlaanderen, Brussels, 308 Belgium).

309 
311 Dachkevitch, T., \& Autran, J. C. (1989). Prediction of baking quality of bread wheats in

312 breeding programs by size-exclusion high-performance liquid-chromatography. Cereal

313 Chemistry, 66(6), 448-456.

314 Guerrieri, N., Alberti, E., Lavelli, V., \& Cerletti, P. (1996). Use of spectroscopic and

315 fluorescence techniques to assess heat-induced molecular modifications of gluten. Cereal

316 Chemistry, 73(3), 368-374.

317 Lagrain, B., Brijs, K., \& Delcour, J. A. (2006). Impact of redox agents on the physico-

318 chemistry of wheat gluten proteins during hydrothermal treatment. Journal of Cereal

319 Science, 44(1), 49-53.

320 Lagrain, B., Brijs, K., Veraverbeke, W. S., \& Delcour, J. A. (2005). The impact of heating

321 and cooling on the physico-chemical properties of wheat gluten-water suspensions. Journal

322 of Cereal Science, 42(3), 327-333.

323 Lagrain, B., Thewissen, B. G., Brijs, K., \& Delcour, J. A. (2007). Impact of redox agents on

324 the extractability of gluten proteins during bread making. Journal of Agricultural and Food

325 Chemistry, 55(13), 5320-5325.

326 Morel, M. H., Redl, A., \& Guilbert, S. (2002). Mechanism of heat and shear mediated

327 aggregation of wheat gluten protein upon mixing. Biomacromolecules, 3(3), 488-497.

328 Redl, A., Morel, M. H., Bonicel, J., Vergnes, B., \& Guilbert, S. (1999). Extrusion of wheat

329 gluten plasticized with glycerol: Influence of process conditions on flow behavior, 330 rheological properties, and molecular size distribution. Cereal Chemistry, 76(3), 361-370. 
331 Schofield, J. D., Bottomley, R. C., Timms, M. F., \& Booth, M. R. (1983). The effect of heat 332 on wheat gluten and the involvement of sulfhydryl-disulfide interchange reactions. Journal 333 of Cereal Science, 1(4), 241-253.

334 Schurer, F., Kieffer, R., Wieser, H., \& Koehler, P. (2007). Effect of hydrostatic pressure 335 and temperature on the chemical and functional properties of wheat gluten II. Studies on 336 the influence of additives. Journal of Cereal Science, 46(1), 39-48.

337 Singh, H., \& MacRitchie, F. (2004). Changes in proteins induced by heating gluten 338 dispersions at high temperature. Journal of Cereal Science, 39(2), 297-301.

339 Veraverbeke, W. S., \& Delcour, J. A. (2002). Wheat protein composition and properties of 340 wheat glutenin in relation to breadmaking functionality. Critical Reviews in Food Science 341 and Nutrition, 42(3), 179-208.

342 Volkin, D. B., \& Klibanov, A. M. (1987). Thermal-destruction processes in proteins 343 involving cystine residues. Journal of Biological Chemistry, 262(7), 2945-2950.

344 Wieser, H., Antes, S., \& Seilmeier, W. (1998). Quantitative determination of gluten protein 345 types in wheat flour by reversed-phase high-performance liquid chromatography. Cereal 346 Chemistry, 75(5), 644-650. 


\section{Fig. captions}

351 Fig. 1. RVA profiles $\left(40\right.$ min at $95^{\circ} \mathrm{C}$ ) of gluten-water suspensions with addition of DTT

$352(6.1 \mu \mathrm{mol} / \mathrm{g}$ gluten) at 0,13 and $30 \mathrm{~min}$. Control viscosity profile (------), DTT at $0 \mathrm{~min}$ $353(-)$, DTT at $13 \mathrm{~min}({ }), \mathrm{DTT}$ at $30 \mathrm{~min}(-)$, temperature (----- ). Arrows 354 indicate moments of addition.

355 Fig. 2. Areas in RP-HPLC chromatogram representing gluten extractability with $60 \%$ 356 ethanol and $0.05 \mathrm{M}$ Tris/ $\mathrm{HCl}$ buffer ( $\mathrm{pH} 7.5)$ with $50 \%$ propan-1-ol, $2.0 \mathrm{M}$ urea and $1 \%$

357 (w/v) DTT after RVA analysis with addition of DTT (6.1 $\mu \mathrm{mol} / \mathrm{g}$ gluten) at 0, 13 and 30 358 min during RVA analysis. Fig. 2a shows the gliadin fraction with $\omega$-gliadin (grey), $\alpha$ 359 gliadin (black) and $\gamma$-gliadin (white). Fig. 2b shows the reduced glutenin fraction with the 360 apparent amounts of D-LMW-GS (grey), HMW-GS (white) and B/C-LMW-GS (black); 361 AU, arbitrary units; C, control gluten suspension; HTT, hydrothermal treatment.

362 Fig. 3. RVA profiles $\left(40 \mathrm{~min}\right.$ at $\left.95^{\circ} \mathrm{C}\right)$ of gluten-water suspensions with addition of 363 potassium iodate $(2.1 \mu \mathrm{mol} / \mathrm{g}$ gluten $)$ at 0,13 and $30 \mathrm{~min}$. Control viscosity profile 364 (------), potassium iodate at $0 \mathrm{~min}(-)$, potassium iodate at $13 \mathrm{~min}(-)$, potassium 365 iodate at $30 \mathrm{~min}({ })$, temperature $(----)$. Arrows indicate moments of addition.

366 Fig. 4. Areas in RP-HPLC chromatogram representing gluten extractability after RVA 367 analysis with addition of potassium iodate $(2.1 \mu \mathrm{mol} / \mathrm{g}$ gluten $)$ at 0,13 and $30 \mathrm{~min}$ during 368 RVA analysis. Fig. 4a shows the gliadin fraction with $\omega$-gliadin (grey), $\alpha$-gliadin (black) 369 and $\gamma$-gliadin (white). Fig. $4 \mathrm{~b}$ shows the reduced glutenin fraction with the apparent 370 amounts of D-LMW-GS (grey), HMW-GS (white) and B/C-LMW-GS (black); AU, 371 arbitrary units; C, control gluten suspension; HTT, hydrothermal treatment. 
372 Fig. 5. RVA profiles ( $40 \mathrm{~min}$ at $95{ }^{\circ} \mathrm{C}$ ) of gluten-water suspensions with addition of NEMI $373(8.0 \mu \mathrm{mol} / \mathrm{g}$ gluten $)$ at $0 \mathrm{~min}$ and GSH at $13 \mathrm{~min}$. Control viscosity profile (------), 8.0 $374 \mu \mathrm{mol} \mathrm{NEMI} / \mathrm{g}$ of protein $(\longrightarrow), \mathrm{NEMI}+3.1 \mu \mathrm{mol} \mathrm{GSH} / \mathrm{g}$ protein at $13 \mathrm{~min}(\longrightarrow), \mathrm{NEMI}$ $375+6.2 \mu \mathrm{mol} \mathrm{GSH} / \mathrm{g}$ protein at $13 \mathrm{~min}\left(-\right.$ ), temperature ( - - $(-)^{--}$. Arrow indicates 376 moment of addition.

377 Fig. 6. Areas in RP-HPLC chromatogram representing gluten extractability after RVA 378 analysis with addition of NEMI $(8.0 \mu \mathrm{mol} / \mathrm{g}$ gluten $)$ at $0 \mathrm{~min}$ and GSH at $13 \mathrm{~min}$ during 379 RVA analysis. Fig. 6a shows the gliadin fraction with $\omega$-gliadin (grey), $\alpha$-gliadin (black) 380 and $\gamma$-gliadin (white). Fig. $6 \mathrm{~b}$ shows the reduced glutenin fraction with the apparent 381 amounts of D-LMW-GS (grey), HMW-GS (white) and B/C-LMW-GS (black); AU, 382 arbitrary units; C, control gluten suspension; GSH1, $3.1 \mu \mathrm{mol} \mathrm{GSH} / \mathrm{g}$ protein at $13 \mathrm{~min}$; $383 \mathrm{GSH} 2,6.2 \mu \mathrm{mol} \mathrm{GSH} / \mathrm{g}$ protein at $13 \mathrm{~min} ; \mathrm{HTT}$, hydrothermal treatment.

384 Fig. 7. Model for gliadin-glutenin cross-linking through SH-SS exchange reactions during 385 hydrothermal treatment. (I.1) In the absence of additives heating to $90{ }^{\circ} \mathrm{C}$ leads to 386 conformational changes exposing previously unavailable free SH-groups and 387 polymerization of glutenin with oxidation of SH-groups. (I.2) Glutenin can link to gliadin 388 at temperatures exceeding $90{ }^{\circ} \mathrm{C}$ through a SH-SS exchange reaction and the generated free 389 SH-group can react further with either gliadin or glutenin. (II.1) Reducing agents first 390 depolymerize glutenin and increase the level of free SH-groups and, hence, (II.2) increase 391 gliadin-glutenin cross-linking. (III.1) Addition of an oxidizing agent decreases the level of 392 free SH and, hence, hinders glutenin linking and gliadin-glutenin cross-linking above 90 $393{ }^{\circ} \mathrm{C}$. (III.2) Subsequent addition of a SH containing agent can introduce new free SH-groups 394 in the gluten proteins and again induce gliadin-glutenin covalent cross-linking. 
$396 \quad$ Fig.s

397 Fig. 1

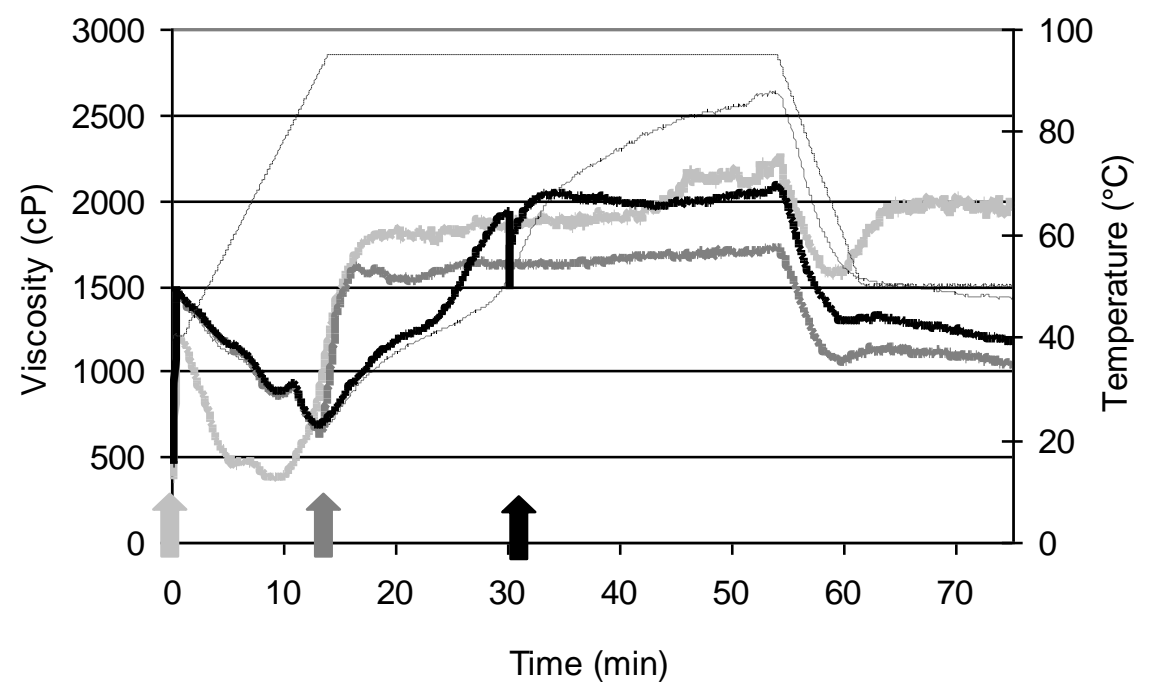

398 
Fig. 2

(a)

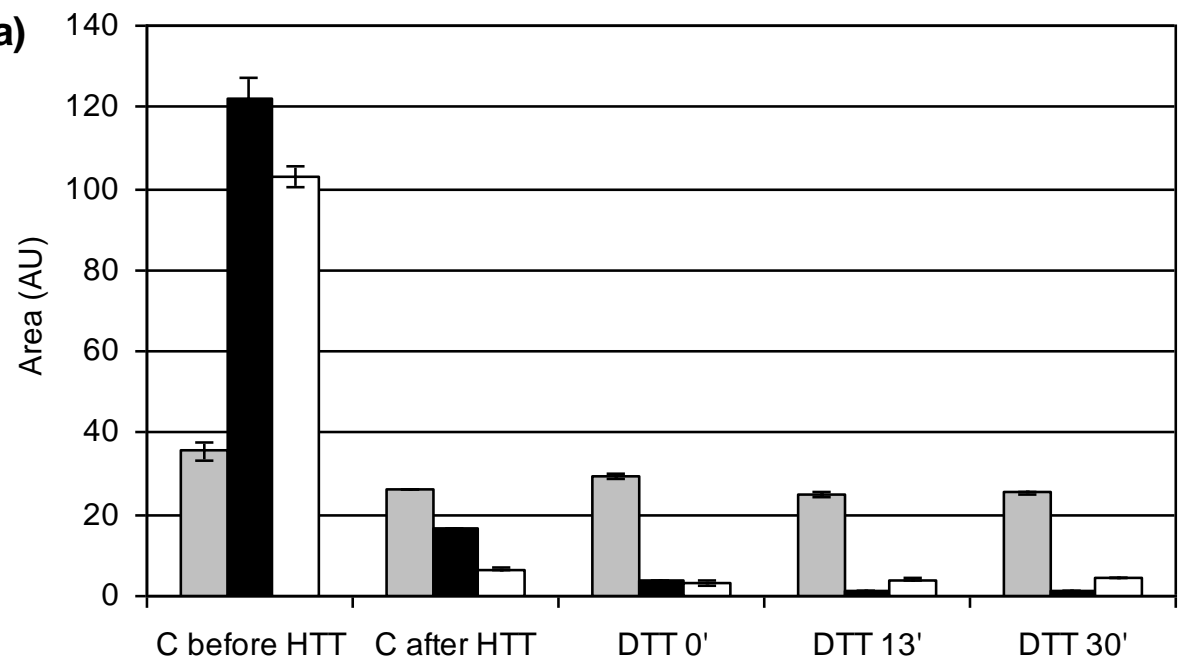

400

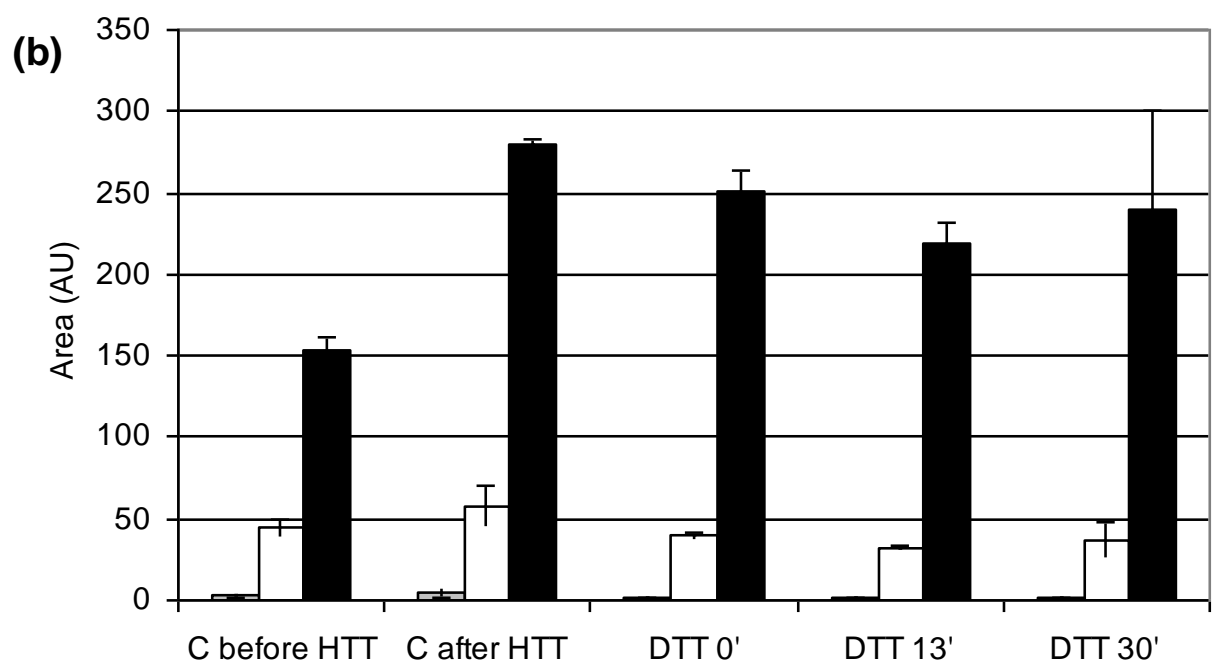

401 
402 Fig. 3

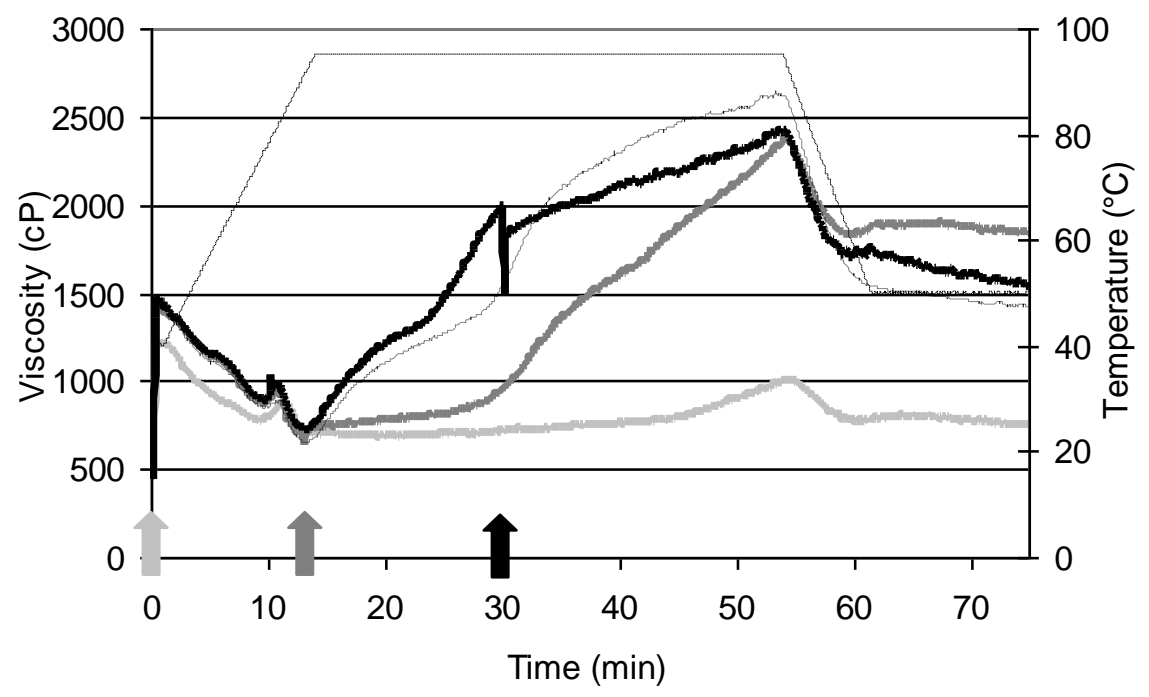

403 
Fig. 4

(a)

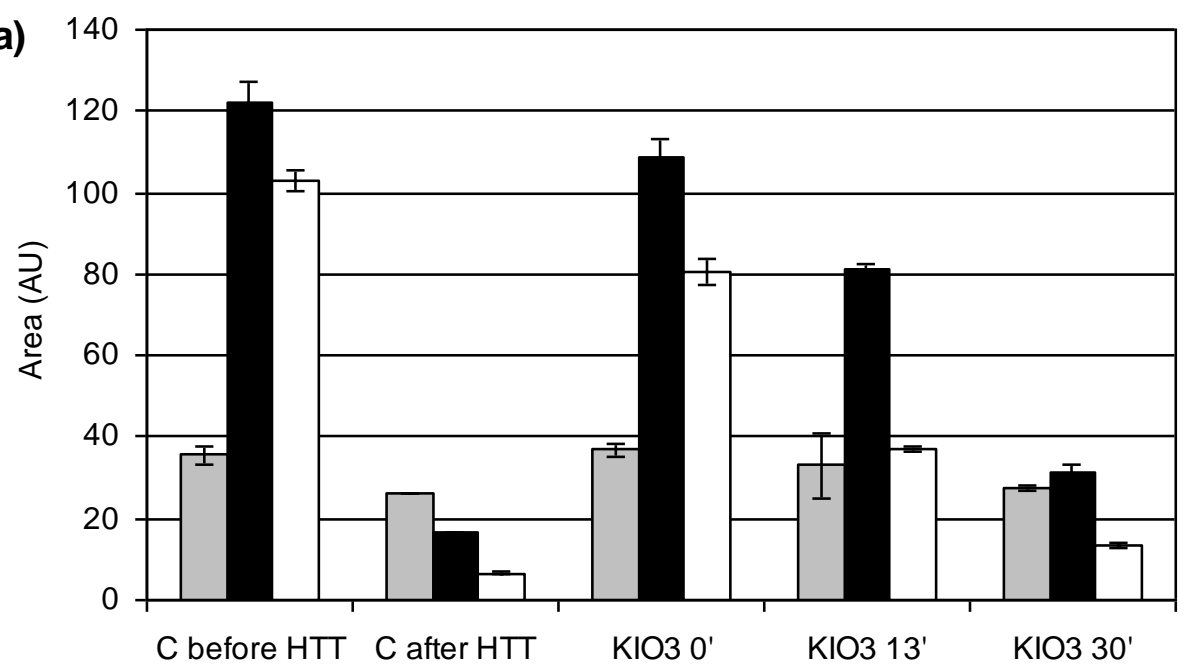

405

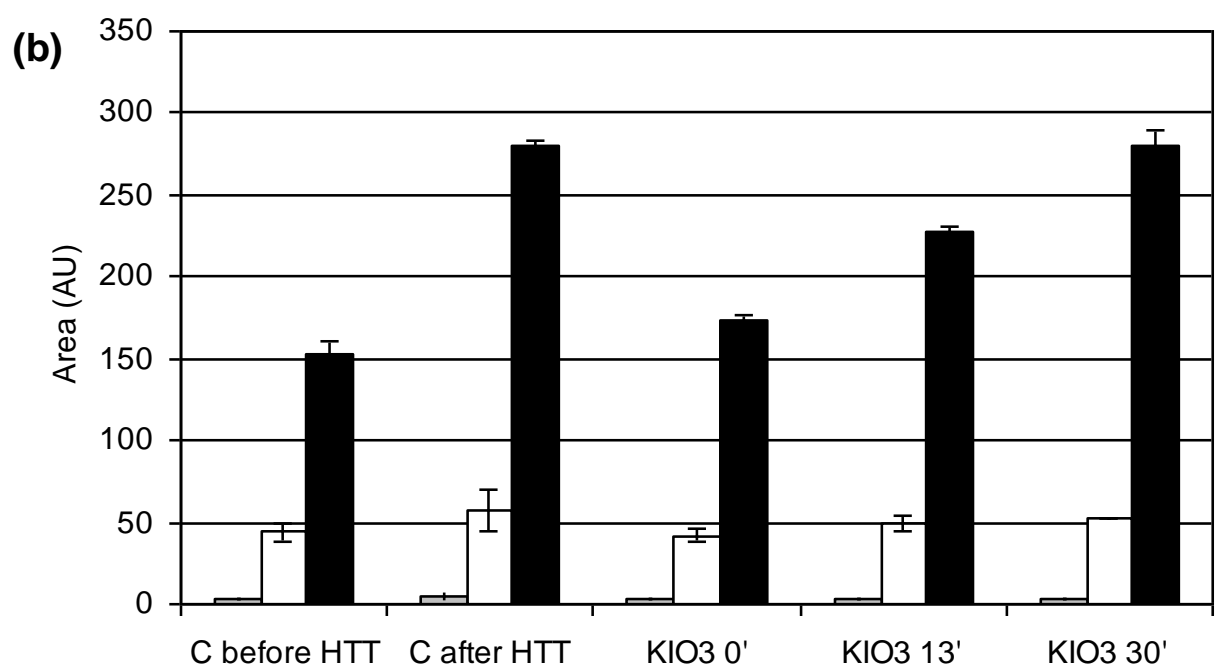

406 
Fig. 5

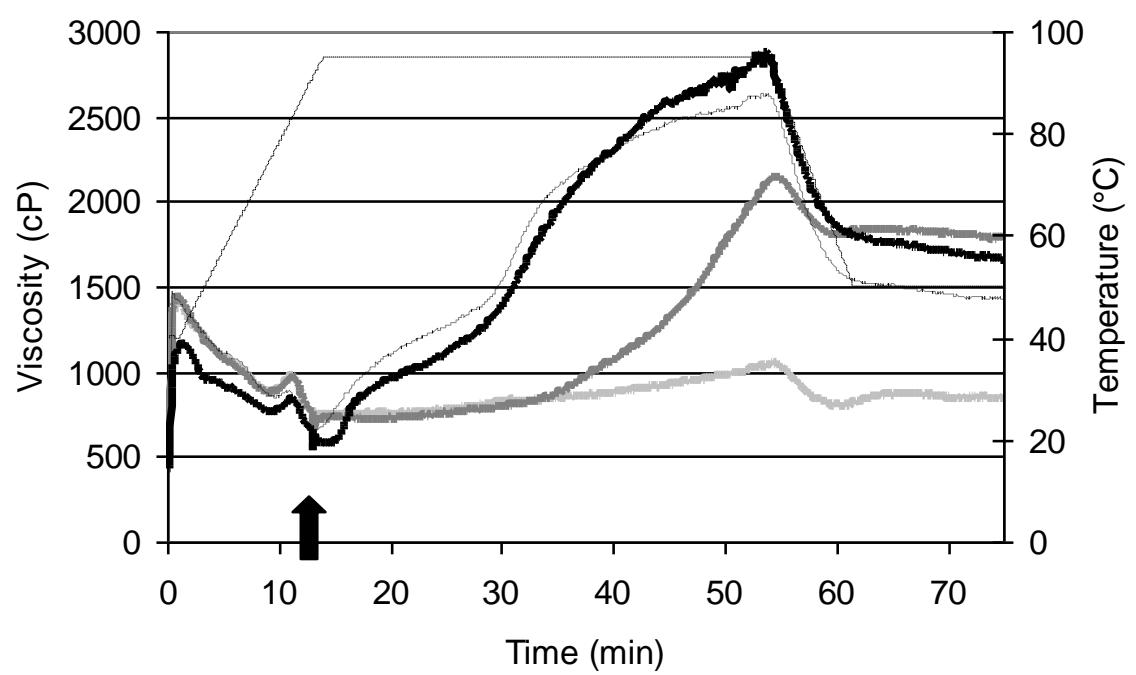

408

409 
410 Fig. 6

(a)

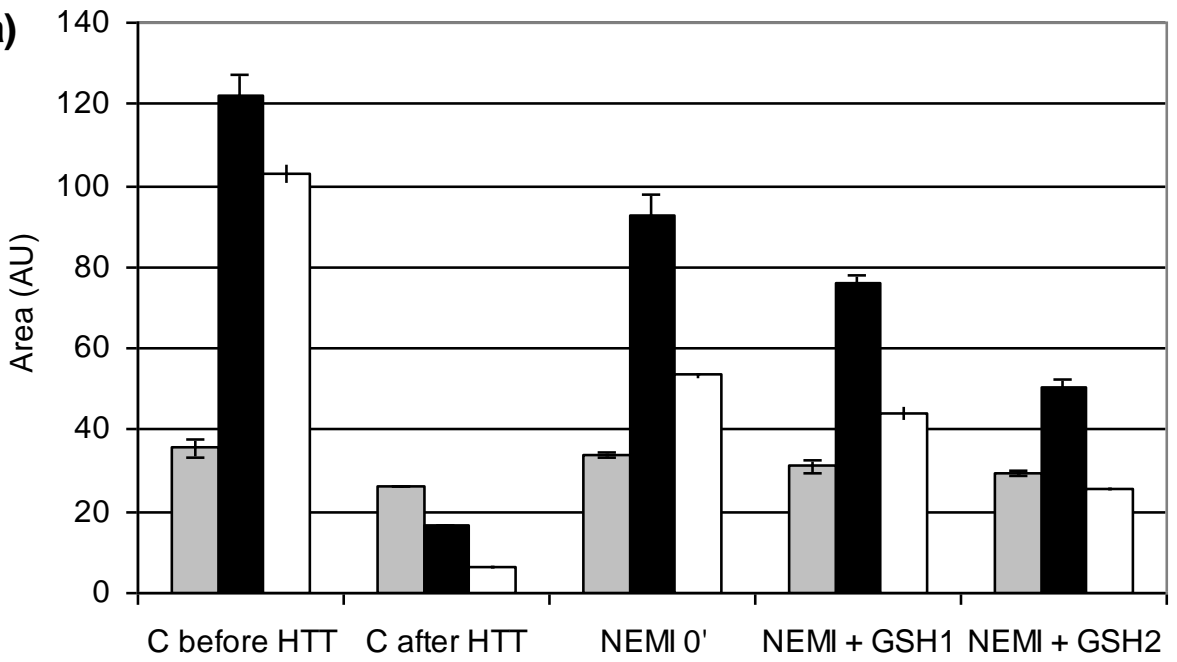

411

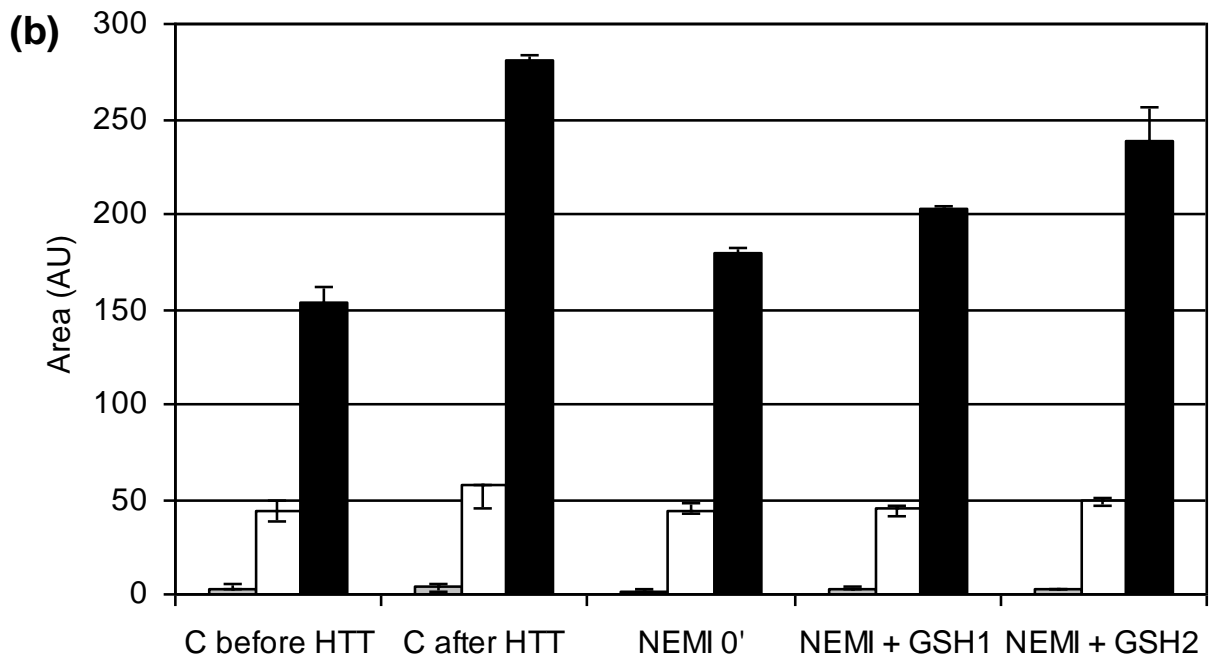

412 
413 Fig. 7 


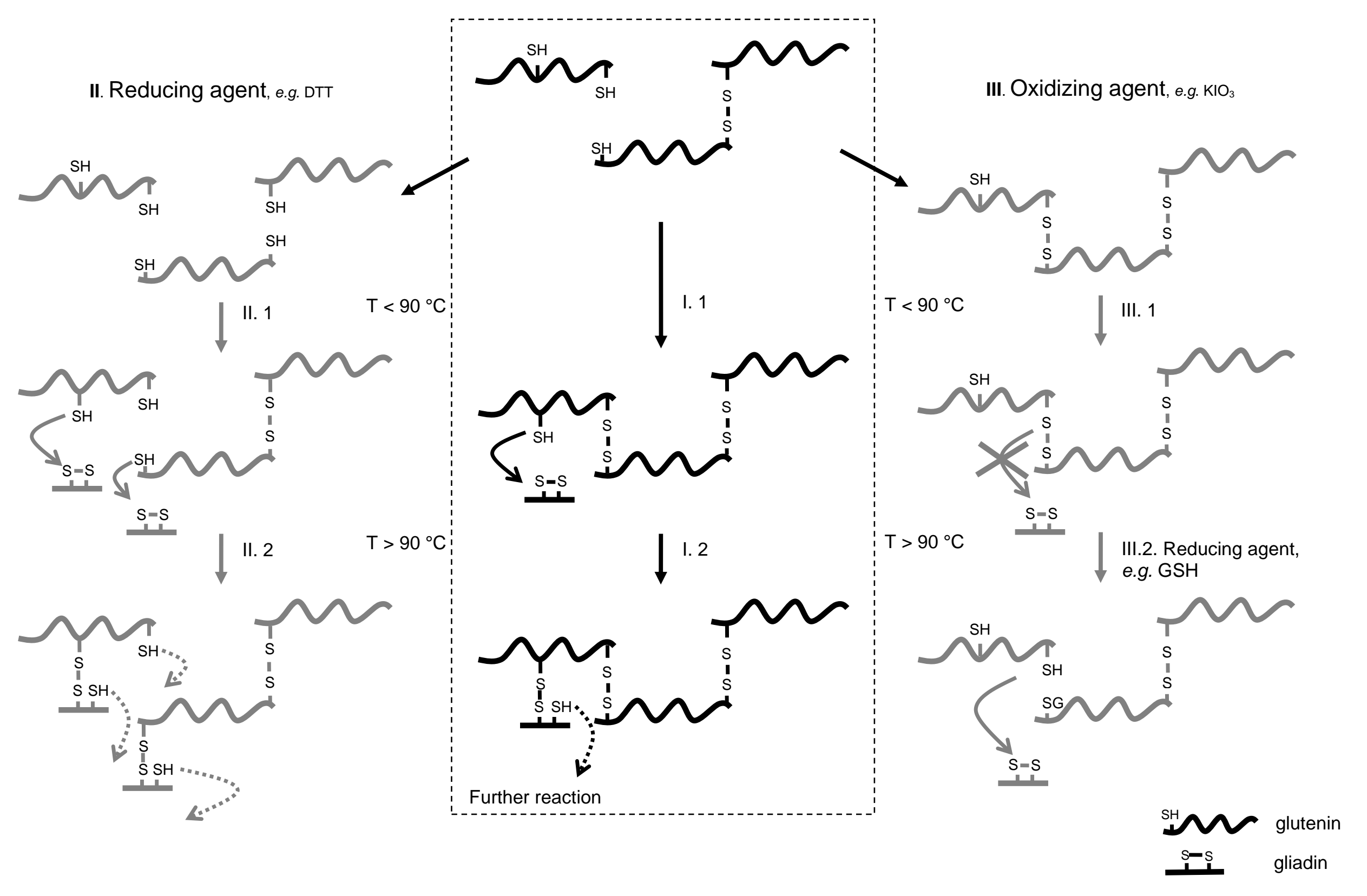




\section{Tables}

416 Table 1. Characteristic RVA viscosities (means of at least 3 observations) of gluten-water

417 suspensions $(20 \% \mathrm{w} / \mathrm{v})$ during hydrothermal treatment in the presence of $6.10 \mu \mathrm{mol}$ DTT/g

418 protein or $2.1 \mu \mathrm{mol} \mathrm{KIO}_{3} / \mathrm{g}$ protein added at $0 \mathrm{~min}, 13 \mathrm{~min}$ or $30 \mathrm{~min}$ during $\mathrm{RVA}$ analysis.

\begin{tabular}{lccc}
\hline Sample & Initial & Minimal & Maximal \\
& Viscosity (cP) & Viscosity (cP) & Viscosity (cP) \\
\hline Control (C) & $1405 \mathrm{a}$ & $662 \mathrm{a}$ & $2587 \mathrm{a}$ \\
$\mathrm{C}+\mathrm{DTT}$ at $0 \mathrm{~min}$ & $1228 \mathrm{~b}$ & $485 \mathrm{~b}$ & $2271 \mathrm{~b}$ \\
$\mathrm{C}+\mathrm{DTT}$ at $13 \mathrm{~min}$ & $1424 \mathrm{a}$ & $605 \mathrm{a}$ & $1864 \mathrm{~b}$ \\
$\mathrm{C}+\mathrm{DTT}$ at $30 \mathrm{~min}$ & $1416 \mathrm{a}$ & $689 \mathrm{a}$ & $2098 \mathrm{~b}$ \\
$\mathrm{C}+\mathrm{KIO}_{3}$ at $0 \mathrm{~min}$ & $1216 \mathrm{a}$ & $682 \mathrm{a}$ & $1010 \mathrm{c}$ \\
$\mathrm{C}+\mathrm{KIO}_{3}$ at $13 \mathrm{~min}$ & $1498 \mathrm{a}$ & $650 \mathrm{a}$ & $2383 \mathrm{a}$ \\
$\mathrm{C}+\mathrm{KIO}_{3}$ at $30 \mathrm{~min}$ & $1428 \mathrm{a}$ & $705 \mathrm{a}$ & $2384 \mathrm{e}$ \\
$\mathrm{Control}(\mathrm{C})$ & $1405 \mathrm{a}$ & $662 \mathrm{a}$ & $2587 \mathrm{a}$
\end{tabular}

419 Values in the same column followed by a different letter differ significantly $(\mathrm{P}<0.05)$.

420 Relative standard deviations were less than $10 \%$ 
421 Table 2. Extractabilities of gluten proteins in 2.0\% SDS containing buffer before or after 422 hydrothermal treatment (HTT) with $6.1 \mu$ mol DTT/g protein or $2.1 \mu$ mol $\mathrm{KIO}_{3} / g$ protein 423 added at 0 min, 13 min or 30 min during RVA analysis.

\begin{tabular}{|c|c|c|c|}
\hline Sample & $\begin{array}{c}\text { SDS } \\
\text { extractable } \\
\text { protein }(\%)\end{array}$ & $\begin{array}{c}\text { SDS } \\
\text { extractable } \\
\text { glutenin }(\%)\end{array}$ & $\begin{array}{c}\text { SDS } \\
\text { extractable } \\
\text { gliadin }(\%)\end{array}$ \\
\hline Control (before HTT) & $80.9(1.4)$ & $25.8(0.4)$ & $55.2(1.0)$ \\
\hline Control (C, after HTT) & $20.4(0.3)$ & $0.8(0.0)$ & $19.6(0.3)$ \\
\hline $\mathrm{C}+\mathrm{DTT}$ at $0 \mathrm{~min}$ & $10.0(1.0)$ & $0.3(0.0)$ & $9.7(0.9)$ \\
\hline $\mathrm{C}+\mathrm{DTT}$ at $13 \mathrm{~min}$ & $11.7(0.9)$ & $0.4(0.0)$ & $11.3(0.9)$ \\
\hline $\mathrm{C}+\mathrm{DTT}$ at $30 \mathrm{~min}$ & $11.7(0.0)$ & $0.2(0.0)$ & $11.5(0.0)$ \\
\hline $\mathrm{C}+\mathrm{KIO}_{3}$ at $0 \mathrm{~min}$ & $51.0(0.1)$ & $4.9(0.0)$ & $46.1(0.1)$ \\
\hline $\mathrm{C}+\mathrm{KIO}_{3}$ at $13 \mathrm{~min}$ & $47.8(0.1)$ & $4.3(0.0)$ & $43.5(0.1)$ \\
\hline $\mathrm{C}+\mathrm{KIO}_{3}$ at $30 \mathrm{~min}$ & $24.2(0.3)$ & $0.8(0.0)$ & $23.4(0.3)$ \\
\hline
\end{tabular}

Standard deviations are shown in brackets. 
426 Table 3. Extractabilities of gluten proteins in 2.0\% SDS containing buffer before or after 427 hydrothermal treatment (HTT) with $8.0 \mu \mathrm{mol} \mathrm{NEMI/g}$ protein at 0 min and GSH at $13 \mathrm{~min}$.

\begin{tabular}{|c|c|c|c|}
\hline Sample & $\begin{array}{c}\text { SDS } \\
\text { extractable } \\
\text { protein }(\%)\end{array}$ & $\begin{array}{c}\text { SDS } \\
\text { extractable } \\
\text { glutenin }(\%)\end{array}$ & $\begin{array}{c}\text { SDS } \\
\text { extractable } \\
\text { gliadin }(\%)\end{array}$ \\
\hline Control (before HTT) & $80.9(1.4)$ & $25.8(0.4)$ & $55.2(1.0)$ \\
\hline Control (C, after HTT) & $20.4(0.3)$ & $0.8(0.0)$ & $19.6(0.3)$ \\
\hline $\mathrm{C}+\mathrm{NEMI}(0 \mathrm{~min})$ & $58.6(0.3)$ & $5.4(0.0)$ & $53.2(0.3)$ \\
\hline $\begin{array}{l}\mathrm{C}+\mathrm{NEMI}(0 \mathrm{~min})+\mathrm{GSH}^{\mathrm{b}}(13 \\
\text { min })\end{array}$ & $44.8(0.1)$ & $2.7(0.0)$ & $42.1(0.1)$ \\
\hline $\begin{array}{l}\mathrm{C}+\mathrm{NEMI}(0 \mathrm{~min})+\mathrm{GSH}^{\mathrm{c}}(13 \\
\text { min })\end{array}$ & $26.3(1.2)$ & $0.9(0.1)$ & $25.3(1.5)$ \\
\hline $\begin{array}{l}\text { a } 3.1 \mu \mathrm{mol} / \mathrm{g} \text { protein } \\
\text { b } 6.2 \mu \mathrm{mol} / \mathrm{g} \text { protein }\end{array}$ & & & \\
\hline
\end{tabular}

